\title{
Dual synchronous primary malignancies involving thyroid and tongue: A rare case review
}

Jyoty Singh", Gautam Kumar Mandal' and Ajit Pratap Singh²

*Correspondence: doctorjyotisingh@yahoo.com

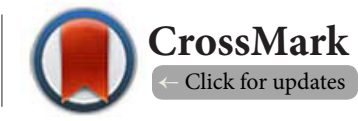

'Department of Pathology, $\mathrm{CNCl}$, Kolkata, India.

${ }^{2} \mathrm{KMC}$ Manipal University, India.

\begin{abstract}
The existence of two synchronous primary cancers in anatomically distinct parts of body is extreemly rare. Here we attended a patient who was a post operative case of Papillary Thyroid carcinoma coexisting with a left sided tongue lesion. We examined the patient clinically and reviewed all the reports. Also Reviewed the thyroid biopsy sample she had with her and confirmed it as well differentiated Papillary carcinoma. Biopsy sample from tongue lesion showed a well differentiated Squamous cell carcinoma. Planning of treatment is very confusing in such difficult situation.
\end{abstract}

Keywords: Field cancerization, squamous cell carcinoma, thyroid and tongue, thyroid transcription factor-1 $(\mathrm{TTF}-1)$

\section{Introduction}

In 1953, Field cancerization was first described as histologically altered epithelium surrounding tumor samples from upper aerodigestive tract [1]. Although field cancerization is very common in head and neck region, two synchronous primary cancers in anatomically distinct organs involving thyroid and tongue is a rare phenomenon [2].

\section{Case presentation}

Our case was a 50 years old female, a post operative case of Papillary Thyroid carcinoma coexisting with a left sided tongue lesion. We examined the patient clinically and found a well healed surgical incision scar on neck and an ill defined white ulcerated lesion over left side of tongue (Figures 1 and 2). Pre operative MRI report was showing a large multi-septate cystic soft tissue mass in right side of neck (Figure 3). The lesion over left side of tongue was showing hyper-intense signal on T2W1 with some enhancement after contrast. There was no significant family history of cancer and radiation exposure of the patient in past. We reviewed biopsy sample of neck swelling and also examined biopsy sample from tongue lesion. Histopathological section from Neck swelling was showing well formed papillae with fibrovascular core (Figure 4). There was high $\mathrm{N}: \mathrm{C}$ ratio, nucei showed grooving (Figure 5). Section also showed psammoma bodies (Figure 6). It was a well dif- ferentiated papillary carcinoma thyroid. Biopsy sample from tongue lesion was showing squamous cell carcinoma cells with well defined cell border, hard eosinophilic cytoplasm, High N: $C$ ratio, pleomorphic nuclei with clumped chromatin. There is keratin pearl formation and these squamous carcinoma cells are infiltrating the underlying muscle. Mitotic figure also can be seen. We diagnosed it as well differentiated squamous cell carcinoma, infiltrating (Figures $\mathbf{7}$ and 8). Although both the malignancies are well differentiated, so we did not require any further investigation to confirm the diagnosis, but Thyroid transcription factor-1 (TTF-1) can be used as an Immune marker in poorly differentiated state to differentiate between these two malignancies. TTF-1 is positive in Papillary thyroid carcinoma but negative in squamous cell carcinoma.

\section{Conclusions}

Utmost care should be taken in diagnosing multiple primary malignancies to rule out metastasis or field cancerization for proper management. The mechanisms involved in the occurence of multiple primary malignancies are not yet elucidated. Some factors such as family history, immunologic and genetic defects, prolonged exposure to carcinogens, and radiotherapy and chemical treatments have been implicated. Even though the majority of multiple primary cancers occur as a result of random chance, the family syndromes of tumors must always 
Singh et al. Journal of Histology \& Histopathology 2016,

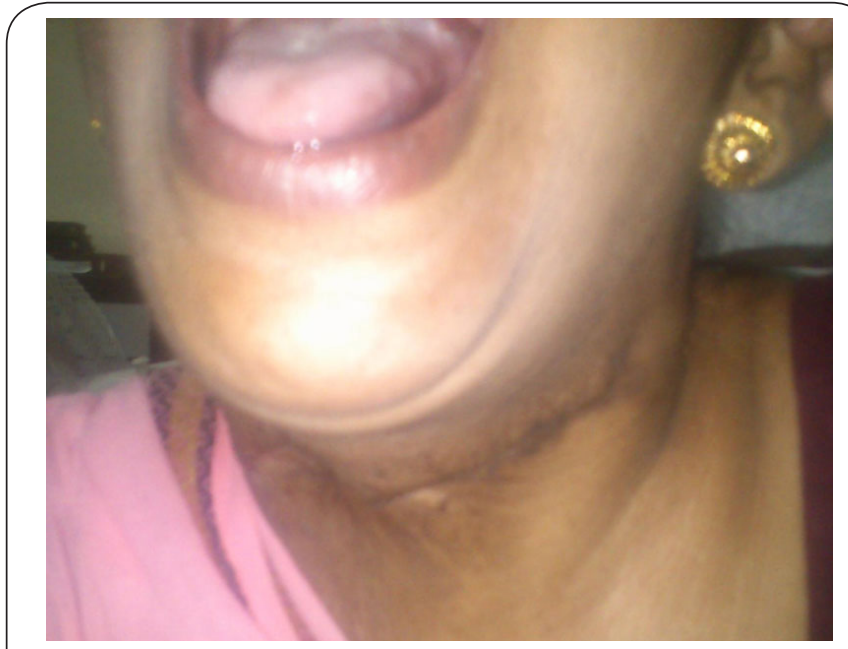

Figure 1. Surgical incision scar on neck.
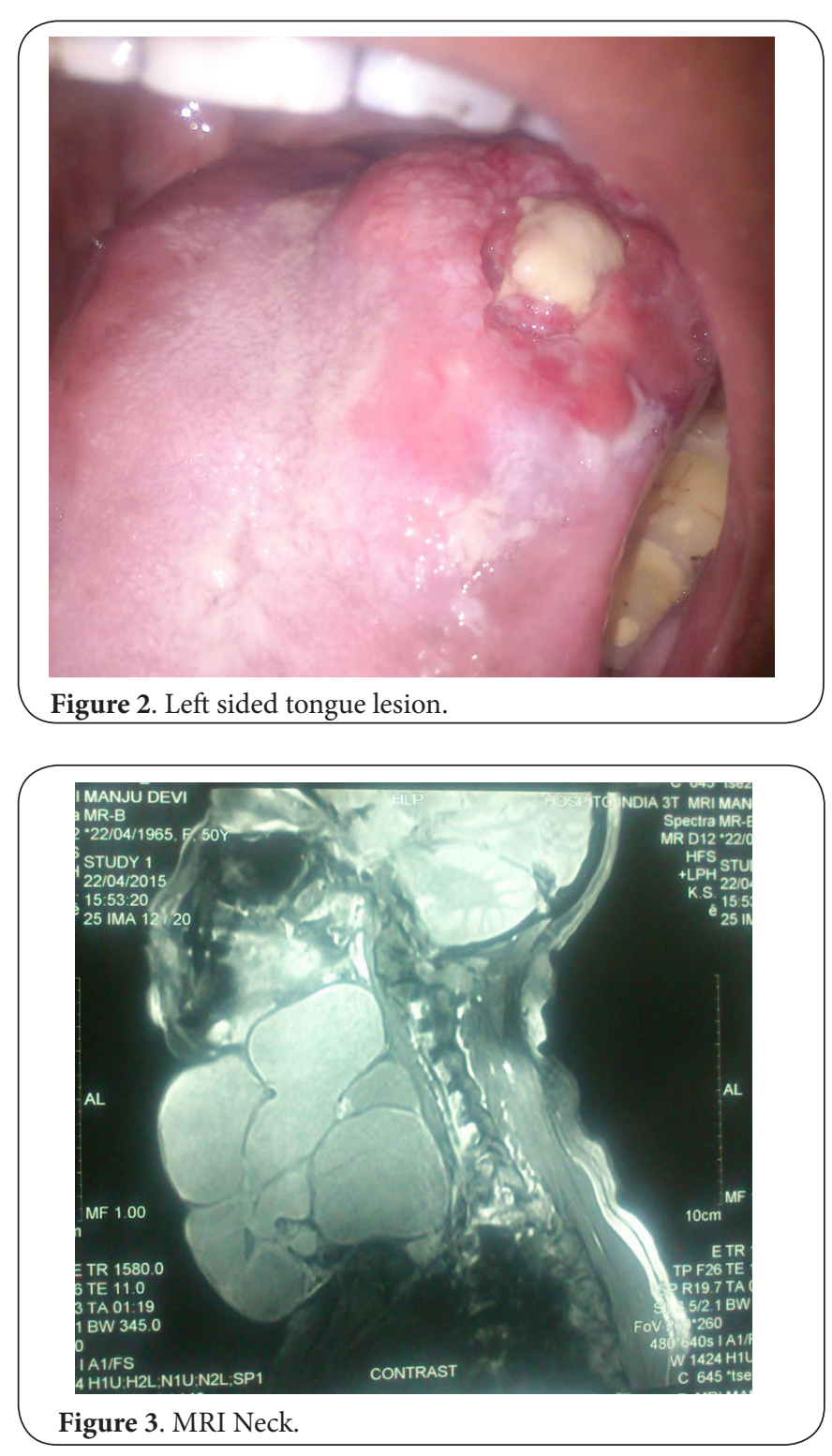

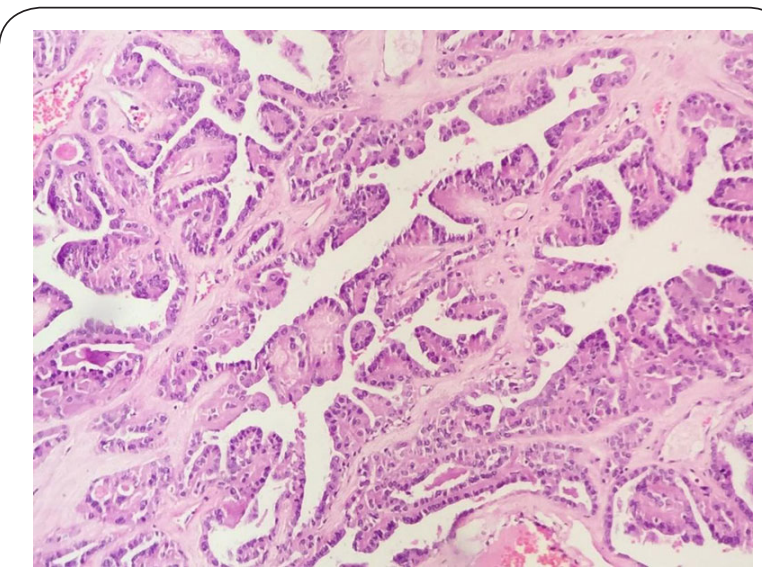

Figure 4. Papillary Thyroid carcinoma (well formed papillae with fibrovascular core).

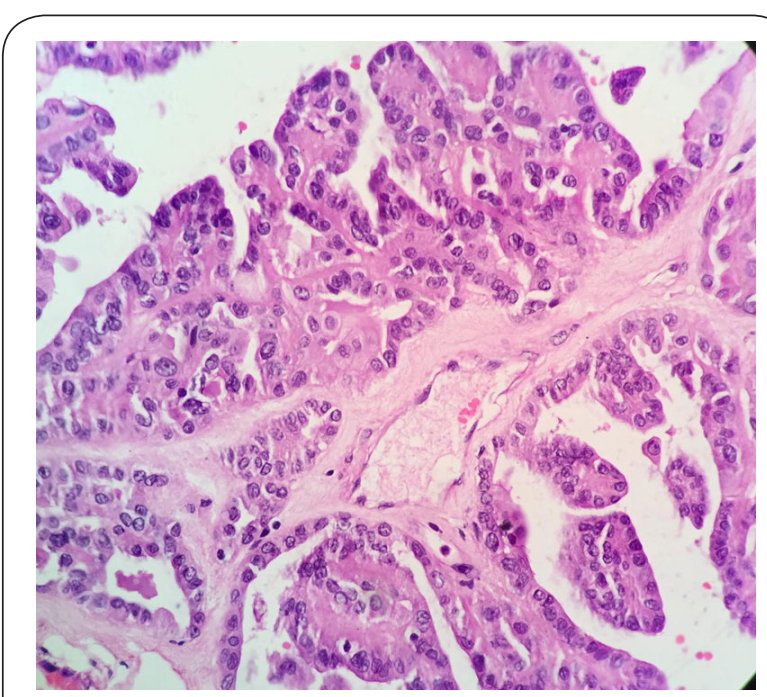

Figure 5. Papillary Thyroid carcinoma (Cells lining the papillae have high Nucleus Cytoplasmic ratio, nuclei with grooves).

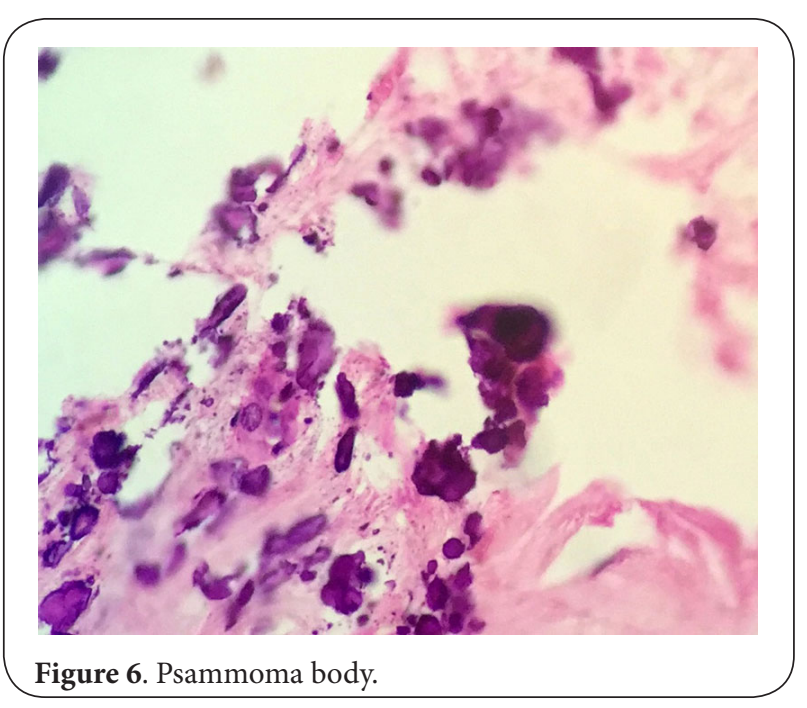




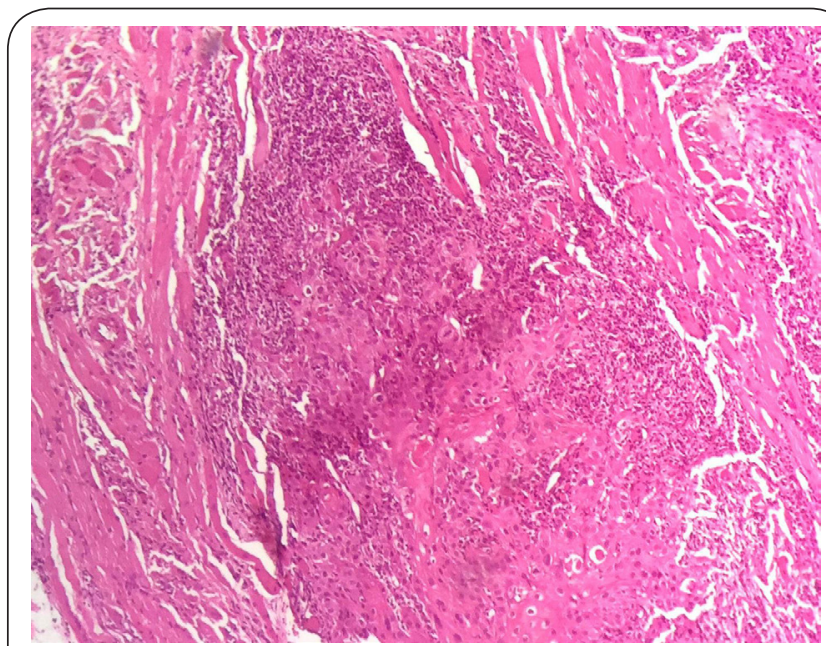

Figure 7. Squamous cell carcinoma cells infiltrating muscles, Nuclei with clumped chromatin.

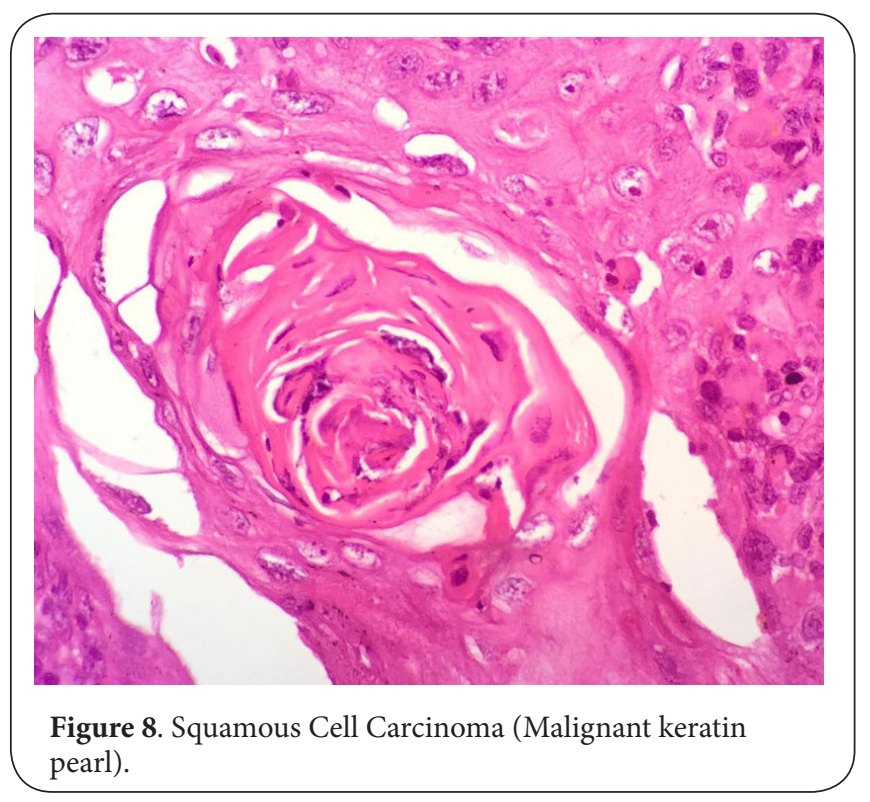

be considered [3].

\section{Competing interests}

The authors declare that they have no competing interests.

\section{Authors' contributions}

\begin{tabular}{|l|c|c|c|}
\hline Authors' contributions & JS & GKM & APS \\
\hline Research concept and design & $\checkmark$ & $\checkmark$ & -- \\
\hline Collection and/or assembly of data & $\checkmark$ & -- & $\checkmark$ \\
\hline Data analysis and interpretation & $\checkmark$ & $\checkmark$ & -- \\
\hline Writing the article & $\checkmark$ & -- & -- \\
\hline Critical revision of the article & $\checkmark$ & $\checkmark$ & $\checkmark$ \\
\hline Final approval of article & $\checkmark$ & $\checkmark$ & $\checkmark$ \\
\hline Statistical analysis & -- & -- & -- \\
\hline
\end{tabular}

\section{Acknowledgement}

Authors would like to thank all the faculty members of department of pathology, $\mathrm{CNCl}$ for their guidance.

\section{Publication history}

EIC: Gaetano Giuseppe Magro, University of Catania, Italy. Received: 08-Dec-2015 Final Revised: 14-Jan-2016 Accepted: 25-Feb-2016 Published: 01-Mar-2016

\section{References}

1. Slaughter DP, Southwick HW and Smejkal W. Field cancerization in oral stratified squamous epithelium; clinical implications of multicentric origin. Cancer. 1953; 6:963-8. | Article | PubMed

2. Verma RK, Tripathi N, Aggarwal P and Panda NK. Metastatic papillary carcinoma thyroid co-existing with oral cavity squamous cell carcinoma: A case report and review of literature. Egyptian Journal of Ear, Nose, Throat and Allied Sciences. 2014; 15:125-128. | Article

3. Campos MEC, Salazar AL and Cabral WLR. A case of synchronous triple primary cancers of the kidney, colon and prostate. Applied Cancer Research. 2012; 32:30-31. | Article

\section{Citation:}

Singh J, Mandal GK and Singh AP. Dual synchronous primary malignancies involving thyroid and tongue: A rare case review. J Histol Histopathol. 2016; 3:2.

http://dx.doi.org/10.7243/2055-091X-3-2 